\title{
PITFALLS OF PROFESSIONAL WRITING - THE MOST COMMON MISTAKES IN WRITING FOR BUSINESS PURPOSES
}

\author{
Antonia ENACHE \\ Marina MILITARU ${ }^{2}$ \\ Viorela-Valentina DIMA ${ }^{3}$
}

\begin{abstract}
The present research looks into the most common inadvertencies that occur in professional writing - more specifically, in writing for business purposes. Against the background of the labour market requirements for professionals equipped with sound writing skills perceived as 'deal makers or breakers' - the paper presents the results of a qualitative analysis of business written assignments of students from an English-taught Business Administration programme organised by the Bucharest University of Economic Studies, Romania. The analysis reveals that, despite students being highly proficient users of the target language, they nonetheless stumble upon challenges that pertain not to accuracy and correctness, but to extraneous factors such as appropriateness, flexibility, conciseness, relevance and deference. In the following, we shall attempt to shed light on these inadvertencies and highlight the aspects to be taken into account when writing in a business context.
\end{abstract}

Keywords: business writing, inadvertency, imprecise language, informal language, students' communicative competence

DOI: $10.24818 / \mathrm{SYN} / 2021 / 17 / 2.07$

\section{Introductory remarks}

The present paper was inspired by the activity of grading business letters and reports submitted online by students from the Bucharest University of Economic Studies - ASE, Romania, during the 2020 coronavirus crisis, more specifically between March and May 2020, when our entire academic activity shifted into the domain of teleworking. The paper also draws on our 18-year experience of teaching business writing and communication to non-native English speakers. Throughout this time, we have become aware of the complexity of the endeavour of developing students' writing skills and would like to highlight some aspects regarding the pitfalls students should avoid in writing for business purposes.

We would first like to briefly refer to a few studies on the necessity of equipping graduates with sound writing skills, as the latter are a prerequisite on the Romanian, European and international labour markets. More specifically, research

1 Antonia Enache, Bucharest University of Economic Studies, antonia.enache@rei.ase.ro 2 Marina Militaru, Bucharest University of Economic Studies, marina.militaru@rei.ase.ro 3 Viorela-Valentina Dima, Bucharest University of Economic Studies, viorela.dima@ase.ro 
on the international labour market requirements for skilled professionals refer to a variety of aspects of interest:

language skills (literacy; receptive skills - reading; productive skills - oral and written communication, presentation and argumentative skills; intercultural skills and global awareness) are either explicitly mentioned as employability skills or may be said to contribute to the development of other key skills (such as logical reasoning, problem solving and analytical thinking, creative thinking, interpersonal skills and teamwork, continuous learning skills)", as well as numeracy and digital skills (Dima \& Ștefan, 2021: 82-83 and references cited therein).

In what concerns (written) communication in foreign languages, in what follows, we refer to the results obtained by studies elaborated by the Organisation for Economic Co-operation and Development, the Council of the European Union and the European Commission, as well as by Ionel (2010), David (2013a., b.) and Dima (2015). Thus, worldwide, writing skills are included in the category of "information-processing skills", together with "reading, [...] numeracy, ICT skills and problem solving" (OECD. Quintini, 2014: 20); the following types of documents are enumerated as written in the workplace on a regular basis: "directions, instructions, memos, e-mails, articles, manuals, books, invoices, bills and forms", as well as letters and reports (idem: 20-21). At European Union level, the "multilingual competence" is part of the key competences for lifelong learning (Council of the European Union, 2018) and it means "the ability to use different languages appropriately and effectively for communication", including knowledge of vocabulary, grammar, registers of language, societal and cultural conventions (idem: 8). In terms of what European citizens use foreign languages at work for, the Special Eurobarometer 386 mentions the following frequently written items: emails and letters (European Commission, 2012: 45).

In Romania, several studies have attempted to find out what English and/or other foreign languages are used for in the workplace. Ionel (2010) investigated the use of English on the Romanian labour market, focusing on the needs of 5 employers: Mercedes Benz Romania - an automobile manufacturer, Raiffeisen Bank, EFG Retail services IFN, Unicredit Tiriac - financial institutions, Hewlett Packard Global eBusiness Operations Center (GeBOC) - an IT company (p. 276). The number of respondents was rather small and heterogeneous - 45 employees from departments dealing in a variety of fields of activity: finance and accounting, human resources, sales and marketing, production, software development (pp. 276277). However, we believe the results obtained are worthy of being mentioned: noticeably, $71 \%$ of the respondents indicated that they used English at work for writing purposes! David (2013a.,b.) also touched upon the needs of learners from the perspective of their use of language skills for personal, academic and professional success, as evident from questionnaire responses provided by students from ASE's then Faculty of Commerce (today's Faculty of Business and Tourism).

SYNERGY volume 17 , no. $2 / 2021$ 
With reference to students' experiences and expectations regarding the use of English for work-related writing activities - the author renders students' perceived need "to write accurate and well-structured CVs or letters of intent", as well as "business letters, reports or e-mails", which are "included in most office employees' job description" (David, 2013b.: 33-34). Dima (2015) was concerned with the contribution of foreign language classes to the moulding of professional economists, and - using a questionnaire distributed to more than 2000 students form all the Faculties of ASE - obtained answers on several aspects, including expectations and concrete examples of the contexts in which foreign languages are used at work. Among the latter, we highlight the fact that "[a]pproximately $50 \%$ of the respondents indicated writing business correspondence" in the workplace ( $p$. 45).

Having revised the national and international need for (business) professionals equipped with sound writing skills, we would like to turn to the presentation of the results of our analysis of Economics students' business writing assignments. More specifically, we have embarked upon a qualitative analysis of a corpus of written assignments submitted online (via the University's platform, online.ase.ro) by students from ASE's Faculty of Business Administration in Foreign Languages between March and May 2020. The corpus comprises the following categories of assignments: business reports (as per the format used for BEC Higher exams, organised by Cambridge Assessment English) and business correspondence (emails, complaints and adjustments), each category being submitted by approximately 125 first-year students as part of the successful completion of the Business English language seminar throughout the second semester of the 20192020 academic year, or as a final test. The written assignments were evaluated on the basis of several criteria: use of English; content and organisation; communicative achievement.

To begin with, it is important to highlight the fact that the level of English of these students is excellent. Prior to being admitted to ASE, some of them already obtained international certifications attesting their language level, such as Cambridge Advanced (CAE), BEC Higher, IELTS Academic or even Cambridge Proficiency (CPE); thus, the vast majority of Business Administration students majoring in English have at least a C1 level. Since they attend an English-taught Economics programme, their proficiency in English was tested during the admission test. During their university studies, they are exposed to English on a daily basis, either during the English-taught Economics subjects, or during the Business English language weekly seminar. During the latter, we noticed that they are proficient users of the target language according to all the internationally accepted standards of assessment (reading, writing, listening, speaking, use of English). They have an almost impeccable mastery of grammar, being familiar with and able to successfully use the most complex structures (such as inversions, subjunctive constructions or mixed conditionals); moreover, their knowledge of the 
English vocabulary is close to that of a native speaker, as they are capable of writing the most intricate and elaborate sentences.

However, when it comes to business writing, there appear to be a number of pitfalls that even the best of students stumble upon. This can be explained in two important ways: on the one hand, since they have just graduated from high-school, they have not yet acquired the professional experience that would enable them to tell the difference between different registers and styles; on the other hand, up until the moment they join the University, most of them have only learned English in a classroom setting, through traditional means (like classic textbooks and more recently, the internet) - therefore, they lack the real-life exposure that would mould their knowledge and teach them the subtleties that come not so much from accuracy, but from the effectiveness of using a foreign language and therefore successfully completing tasks. In the following, our research attempts to shed light on the aspects that appear to be imperfect when the students' business writing skills are being assessed ${ }^{4}$.

It is our firm belief that the results of our analysis - which we present below - can only benefit students and help them understand that further writing practice is needed, despite their already high proficiency in English. We hope that our analysis may help students liaise with Garner's (2012) words:

Supervisors, colleagues, employees, clients, partners and anyone else you communicate with will form an opinion of you from your writing. If it's artless and sloppy, they may assume your thinking is the same. And if you fail to convince them that they should care about your message, they won't care. They may even decide you're not worth doing business with. The stakes are that high. [...] Those who write poorly create barriers between themselves and their readers; those who write well connect with readers, open their minds and achieve goals. Garner (2012: xv)

\section{Significant writing inadvertencies}

Broadly speaking, the most common inadvertencies that can be found in our students' writing can be split in two general categories: inadvertencies pertaining to the use of language, and inadvertencies pertaining to the very content of the letter or report. The first group includes those situations where students appear to be unfamiliar with the different styles and registers of language, as they are insecure when dealing with language specificities required by a particular occasion, context,

4 Similar aspects have been pointed out by Mureșan (2012), in a study concerned with the academic writing skills of students in Economics: "even students with a high level of English language fluency do not find it easy to comply with the requirements of academic writing. The main areas where they encounter difficulties [...] could be summarised as: appropriacy of structuring and organisation of ideas, awareness of the differences of register and style existing among various text types, content- and approach-related aspects [...].” Mureșan (2012: 107)

SYNERGY volume 17, no. $2 / 2021$ 
purpose and audience. We believe that problems in this area are directly determined by the students' lack of professional experience, as well as by their exclusively academic background. By contrast, the inadvertencies related to the content of the report have nothing to do with their knowledge of the language or with their awareness of the professional situation at stake - they are simply caused by the difficulties some students have when organizing the ideas they aim to put across.

\subsection{Inadvertencies pertaining to language}

As we have said at the beginning of our research, the students whose papers we analysed are all highly proficient in English - hence, they use language accurately and correctly, a skill they have acquired since childhood and have brought close to perfection over the years. However, the way they write, the way they construct sentences, the vocabulary choices they make all indicate a difficulty in noticing the difference between what is appropriate and what is inappropriate in a business context, an inability to break away from the theoretical rules they have learned in school and to apply their knowledge flexibly and adequately in order to adjust to a professional setting. In the following, we shall look into the most obvious inadvertencies in their use of language, also attempting to explain these flaws and to make suggestions for better, more customized language choices.

\subsubsection{Imprecise language}

One of the most common mistakes students make when writing for business purposes stems from their tendency to use imprecise language structures when they should be precise, providing exact information. Thus, when conveying details about facts and figures, instead of the specific numbers they ought to include, they resort to imprecision (i.e. lexical vagueness, achieved by lexical items such as things, and so on, etcetera, and grammatical structures - "generic terms and collective nouns", such as lots of or colloquial words for approximating number or quantities, see Crystal \& Davy, 1975: 74-75). Thus, amongst the letters and reports graded in the 2020 summer session, we frequently came across structures like the following:

"High amounts of products can be found on the supermarket shelves".

"Our advertising strategy has turned out to be efficient, as can be seen from the large number of downloads of the flyer".

"This candidate has a low chance of being shortlisted for the interview".

"This will probably result in an increased number of sales."

While imprecision can be a wonderful thing in literature or even in opinion essays, it is a less felicitous choice when it comes to business writing. Imprecision helps convey feelings, emotions, viewpoints and opinions, fosters ambiguity and capitalizes on the beauty of the written word to a great extent; however, the same flexibility that sets the stage for subjectivity, interpretation and a wide array of 
meanings can turn into a catastrophe when the purpose of writing is by definition that of putting forward clear, specific facts. Not only can imprecision confuse and even irritate the reader, it can also result in the conveyance of a meaning different from the one the writer had in mind.

Students also turn to imprecise language by using an abundance of qualifiers (words that limit or enhance the meaning of other words, e.g. "truly successful", "really effective") and hedge words such as might, perhaps, hopefully, possibly, would, could, seems, almost, etc. While the use of these words is not wrong in itself, it is not the best choice when writing for business, as it also enhances imprecision. Overusing qualifiers and hedge words not only fails to deliver exact information, but also makes the writing sound chaotic and lazily constructed, as if the message initiator did not bother to take the necessary time to think about the specific information they needed to transmit. The writer appears to be holding back, reluctant to commit to an exact message; this kind of writing spawns uncertainty and relativity rather than precision and firmness, thus jeopardizing the business relationship at stake.

In our opinion, there are several reasons why students fail to grasp this inadvertency and turn to imprecise language. On the one hand, their own academic background may act as a liability, since "the rules of academic writing don't apply to the business world." (Canavor, 2017: 88) While the academic system aims to provide students with a substantial amount of theoretical knowledge, it is also "not geared to getting things done, but rather to thinking about them" (Canavor, 2017: 36). While accumulating knowledge and contemplating ideas is fundamental for study, in real life situations, especially in situations involving finances, the theoretical educational backgrounds runs the risk of becoming a downside, as it comes to clash with particular requirements. In business, the purpose of writing may cover a wide range of situations, from asking for information to persuading customers (Talbot, 2016: 17), but it is always practical and fact-oriented. While academia rewards imagination and multiple meanings, the business world offers a cold, fact-focused, problem-solving environment where precision and specificity are of the essence; consequently, the shift from theory to practice can turn into a challenge students have difficulties overcoming.

On the other hand, instinctively, resorting to imprecise language rather than accurate facts presents in itself several advantages for the writer, who feels more comfortable when using this style. Imprecision allows for putting a personal spin on things, thus reflecting the writer's own feelings and opinions - for instance, by saying that a particular advertising strategy has resulted in "a significant increase in sales" , the writer conveys the message that the outcome was a positive one - a fact

5 As an anonymous reviewer of this article has pointed out, this phrase "is a perfectly valid structure in business language, usually backed up by figures"; however, in the piece of 
in itself more relevant for them than a specific percentage would be. Similarly, by writing something along the lines of "The company making staff redundant is a serious possibility", the writer conveys a feeling of personal worry rather than the actual likelihood of that happening. In either case, the personal involvement of the message initiator as well as their emotions appear to prevail over the bare facts. Moreover, vague language entails less responsibility for the writer than a specific figure would, a fact that provides mental comfort and allows for more freedom of expression. However, the most significant downside of using imprecise language is that meaning itself is directly impacted - when facts are overshadowed by emotions, clarity suffers and the goals may not be achieved - it is for this reason, too, that imprecision is inappropriate in business writing.

\subsubsection{Informal language}

One of the aspects that is particularly difficult to grasp even by highly proficient users of English pertains to differentiating between different levels of formality, or registers; consequently, students also tend to incorporate informal elements into a document that should be formal, or at least semiformal in style.

Language theorists generally agree on the existence of several registers (Nordquist, 2019), such as: the frozen or static register ("refers to historic language or communication that is intended to remain unchanged, like a constitution or prayer"; the formal register (less rigid but still constrained, used in professional, academic or legal settings where communication is expected to be deferent), the consultative register (used in conversation, mainly when asking from advice from someone with specialized knowledge), the casual or informal register (used when interacting with people we know well, such as co-workers, friends and family) and the intimate register (used only with those we are extremely close to). Alternatively, other theorists identify the existence of a familiar register - on the formality spectrum, it falls under the scope of the informal register, above the intimate one - thus, it is used amongst people who know one another very well, it is characterized by a lack of grammar, spelling and punctuation and it often resorts to slang; also, there exists a ceremonial register, which is rarely used today and "may be encountered when reading transcripts of speeches or historical documents (Lund University, 2011). Additionally, in recent years, we have witnessed the advent of what has been called the semi-formal register (Marinescu, Nicolae and Șerban-Oprescu, 2019: 233), situated in-between the formal and informal ones in that, although it is significantly less rigorous and strict than the formal style (allowing, for instance, for the use of verb contractions and phrasal verbs), it still preserves a significant number of formal elements and, most importantly, the

student writing we are citing, the phrase is not completed by any reference to the actual amount of the increase, i.e. to any figures, which is why we consider it an example of imprecise language.

SYNERGY volume 17 , no. $2 / 2021$ 
distance and neutrality that are required in professional settings. Broadly speaking, we can say that the semi-formal register has emerged in response to both the requirements of popular culture (Lilleker, 2006: 157-159) and to the increased interactivity of human relations in the online world.

In recent times, professional communication across the board has shown a marked shift from a formal, academic, deferent style to a more casual, less formal one. This change is visible everywhere: in academic writing, in political communication, in journalism, in all types of work-related interaction. We believe that globalisation, interconnectivity, interdisciplinarity, multiculturalism, alongside the advent of the internet and the rise of the email and of social networks as the main channels of communication have all contributed to the increased informality of language. The use of language has adapted to present realities, reflecting the break from the past as well as the existing mentalities, attitudes and lifestyle. Everyone is closer in the "multi-screen world" (Merchan, 2018) that is the office of today; hence, through the screen, as physical and social distances wane, the increased familiarity with everyone else translates into a more casual use of language.

"In the middle of the $20^{\text {th }}$ century, business was conducted in a much more impassive, formal way than it is today. (...) The writing that evolved then became very formal, using long-winded, quite overbearing language." (Taylor, 2012: 29) By contrast, business today is conducted in a less formal manner, its main purpose being that of building long-lasting professional partnerships based on the parties knowing and trusting one another as well as interacting in a natural, more relaxed manner. In fact, the long-term success of any business venture relies, to a great extent, on how appropriately and efficiently language is mastered.

However, there is a fine line between writing in a business-casual way, and taking the extra step towards an overly informal language style. While the writing should ideally be "accessible, direct, concise and clear, simple, engaging and persuasive" (Canavor, 2017: 36), deference towards the reader and increased attention to their feelings ought not to be overlooked. A writing style that transgresses the boundaries of the semi-formal one into the informal or even familiar one will convey an impression of excessive, inappropriate familiarity and will likely irritate or even annoy the recipient.

Naturally, most of our language choices depend on how well we know the interlocutor, on how long we have been doing business together and, last but not least, on cultural considerations. Significantly, whenever one is drafting a written document, one must bear in mind that the reader's first and foremost response is an emotional one. While, rationally, they are expected to have a reaction to the concrete facts presented, emotionally, their primary reaction is to how the message is crafted. In order to make sure that the basic response is positive, the message writer must strike the right balance between friendliness and deference - this will 
convey trustworthiness, responsibility and empathy, or absence thereof. Also, the writer will come across as a credible business partner - credibility comes with hard work, engagement and respect for the interlocutor.

Therefore, the excessive use of informal words, phrases and idioms represents an infelicitous choice in business writing, as it reflects poorly on the message initiator, conveys an impression of sloppiness and inconsideration, and may impact message efficiency even before the bare facts have been processed by the recipient. Among the papers submitted by the students, words and phrases like the following occurred frequently:

- informal nouns used instead of their more formal equivalents: boss instead of employer, job instead of employment / vacancy / opening / occupation, peers instead of colleagues / co-workers, chance instead of opportunity, lack instead of deficiency/shortage / absence, etc.;

- an abundance of informal verbs instead of their formal counterparts: to check instead of to verify, to get instead of to receive / to obtain or to become, to help instead of to assist, to hurt instead of to harm / to damage / to (negatively) impact, to boost instead of to improve / to enhance, to sack instead of to fire, etc.;

- some informal adjectives instead of their formal equivalents: old instead of elderly / senior (in this case, the choice is not only too casual, but also politically incorrect and possibly offensive), cheap instead of inexpensive (students fail to grasp the negative connotations of cheap, which is traditionally interpreted not only as not expensive, but also low quality), empty instead of vacant, big instead of significant / considerable, etc;

- some phrasal verbs: to call off instead of to cancel, to put off instead of to postpone, to point out instead of to indicate / to highlight / to emphasize, to carry out instead of to conduct, to set up instead of to establish / to found, to settle for instead of to choose / to opt for, to look into instead of to investigate / to analyse, to ask for instead of to request, to deal with instead of to handle / to manage / to tackle - what is remarkable about phrasal verbs is that, while initially they were considered informal, they have gradually made their way into the semiformal style and many of them have come to be accepted in professional settings; however, in contexts that are very strict, there is always at least one formal equivalent that is not a phrasal verb and that would represent a more felicitous language choice. Moreover, there are some phrasal verbs that can only be labelled as informal, familiar, even slang, such as "to rip off" (to swindle / to defraud) or "to rack up" (to accumulate) - these are never to be used in a professional setting;

- some parts of speech that have changed their word class by the procedure known as "conversion" (Yule, 2020: 63): to up instead of to raise / to increase, to better instead of to improve - this linguistic procedure, whereby there is a world class change that is not the result of affixation, has been coined "functional conversion" (Lancaster University, not dated) and is used for rhetorical purposes, to enhance impact; however, newcomer words are still perceived as informal and may come across as inappropriate; 
- many informal idioms, expressions and phrases: a lot of / lots of, a bit of, keep tabs on, start from scratch, make ends meet, put the business out there, top notch, do one's best, all over the place, not to have a clue etc.

It is important to reiterate that, while some informal choices are in order, others are not. For instance, while to buy is a perfectly acceptable version of to purchase, and is even to be preferred in some cases, or to choose may be a better choice than to opt for in most contexts, the excessive use of idioms like a lot of runs the risk of conveying an impression of familiarity and even sloppiness, thus irritating the reader. The same applies to intensifiers such as pretty instead of quite or rather (as in pretty mисh) or way instead of mисh (way more expensive instead of much more expensive). Aside from the fact that intensifiers are to be avoided altogether, as they are not precise, in this case the more formal version is preferable. It also goes without saying that opting for the more or less formal possibility of conveying the same message draws on a variety of factors including aspects pertaining to power and distance, culture, business relationship and future prospects of the partnership. Overall, we can say that identifying which language choice is the most appropriate one in a given context derives from the writer's communicative competence, "the general ability to use language accurately, appropriately and flexibly" (Yule, 2020: 227) - more specifically, from their sociolinguistic competence, which translates into appropriate use, strategic competence and flexible use. The recognition and successful application of these nuances goes beyond grammatical competence (the ability to write correctly, or the "knowledge of, and ability to use, the grammatical resources of a language", Council of Europe, 2001: 112), involving a wide variety of extraneous facets the acquisition whereof is not ensured by the students' academic background.

\subsubsection{Other inadvertencies pertaining to language}

Apart from the use of imprecise language and the use of informal language, there exist other shortcomings that show students need to work on improving their communicative competence, as their insufficient exposure to real-life situations takes a toll on their professional skills. Thus, amongst other inadequacies that were identified in the papers submitted, we have found that the following occurred frequently and are deemed more likely to negatively impact the message and to therefore harm business communication in the long run:

\section{a. The use of long, convoluted sentences.}

Yet again, a possible explanation for this phenomenon stems from the tribute students pay to their academic background, as "academia traditionally rewards dense, complicated, convoluted writing full of expensive words" (Canavor, 2017: 36). Once obligated to change the setting, students find out first hand that there is a clash between the theoretical background and real-life requirements. As we have said before, while in the traditional teaching of foreign languages, a strong 
emphasis is placed on accuracy and on enabling students to emit and discuss theoretical ideas, by contrast, "business writing always has a goal and is geared towards action (Canavor, 2017: 36). Moreover, in the Romanian educational system, high school teachers and even university professors sometimes assess writing that is dense and complicated in a favourable way, as a compelling display of how well a student masters a foreign language; hence, the latter ends up thinking that long, convoluted sentences make them look smarter. In professional situations, however, the criteria at work change - writing has to be simple, clear, readerfriendly and goal-oriented. Therefore, students are basically asked to break away from everything they have been taught and from all the rules they knew were at work in gauging their performance, and to organise their writing according to a completely different mindset: that in business writing, "less is usually more" (Canavor, 2017: 133) - it is for this reason that they sometimes stumble upon difficulties and have to work towards improving the efficiency of their message.

\section{b. A tendency to slip towards a writing style that is essay-like and / or too casual}

This is difficult to pin down and describe in concrete detail; however, it includes a set of aspects that are easily recognisable in a piece of writing. Among these, we have identified a preference for playing on feelings rather than facts, the inability to express opinion in an objective, detached way, the use of hyperbolic and / or excessively persuasive language, the use of figures of speech like metaphors and comparisons, the use of emotionally charged words, language and punctuation (for instance, adjectives like tremendous, outrageous, great, disastrous etc. are to be avoided, as they betray the emotional involvement of the emitter rather than conveying bare facts), the excessive use of intensifiers (such as "a truly successful advertising campaign", "really effective strategies") - these are also to be avoided as they represent non-contributing words, they bring no new information but only overload the writing. Equally, they tend to resort to too many linkers and to narratives, they recount facts that have nothing to do with the issue at stake, and are inclined to add a personal touch to their writing, as they believe it will make the message more fun and will highlight their personality. For instance, they may use an abundance of rhetorical questions (e.g.: "How will the customer respond to this type of campaign?"), they choose to resort to humour (which is not a good idea in formal contexts, while in cross-cultural communication it is downright counterproductive, as it is unlikely to be understood and may irritate or even annoy the recipient) or even to irony and sarcasm, which are even worse and almost certain to generate a negative reaction at the other end of the communication channel. "Humour, irony and sarcasm are to be avoided, as they can be misinterpreted and act against your interest" (Canavor, 2017: 248).

As we have said already, students sometimes use an abundance of non-contributing words - extra words that neither effectively support the core meaning, nor bring any extra information. These dilute the strength and focus of the writing and include, alongside intensifiers which we have mentioned, unnecessary prepositions, phrases, too many descriptive words and modifiers like adverbs or adjectives,

SYNERGY volume 17, no. 2/2021 
which are repetitive or even completely useless, as they convey the same idea, and also too many clutter words (as a matter of fact, in order to, at this point in time etc.), which also represent layers of padding added to the message without contributing to the core meaning at all.

To conclude this subsection, we can say that students have a tendency to use empty rhetoric rather than substance and they find it difficult to draft short, simple sentences focusing on facts, devoid of unnecessary linguistic baggage and keeping to the point, which is exactly what writing for business should be about.

\subsection{Inadvertencies pertaining to content}

The content of a text plays a crucial role in its efficiency, alongside the way in which language is used (ideally, it ought to be used accurately, appropriately and flexibly). Its content, or the relevant issues that are to be highlighted, has to be structured, displayed and organised in order to achieve a positive impact: to inform or persuade the reader and to leave them with a good overall impression of writer and the business relationship. In other words, "good writing is good thinking presented clearly, concisely, and transparently in ways that make sense to your readers" (Canavor, 2017: 34). Clarity, focus, organisation of ideas, credibility and, last but not least, a positive emotional impact are all important aspects to take into account when assessing the success and efficiency of a written text.

While the content of a text depends on a variety of factors, among which the most important are the audience and the goal of communication, there is a set of features that all texts must comply with, especially in a professional setting where longlasting business partnerships are at stake. Beaugrande and Dressler define a text as "a communicative occurrence which meets seven standards of textuality (Beaugrande and Dressler, 1981: 3): cohesion (the actual words we see should be mutually connected within a sentence; coherence (the concepts and relations underlying the surface text should be mutually accessible and relevant); intentionality (the text producer should intend to attain a goal in a plan); acceptability (the text receiver should acquire knowledge through that text); informativity (the text should, at least to some extent, provide new information); situationality (the text should be relevant to a certain situation) and intertextuality (defines the factors that make the understanding of a text dependent of knowledge of other previous texts).

With these clarifications in mind, our analysis of students' written assignments ${ }^{6}$ has revealed that in business writing, as the students' knowledge of English is good to excellent, cohesion is not an issue; however, they sometimes stumble upon grasping all the elements pertaining to coherence (for instance reason, causality or

${ }^{6}$ For reasons of space, we cannot provide large chunks of student assignments for exemplification purposes.

SYNERGY volume 17 , no. $2 / 2021$ 
purpose); also, informativity and intertextuality may sometimes generate challenging situations. Also, it is important to point out that the seven standards of textuality are not independent from one another; they are interrelated, and often violation of one standard may translate into the consequent infringement of others. The coherent organisation of ideas in drafting a text is a generally applicable concept; broadly speaking, we can say that the most important content and information, the most relevant facts ought to appear in the main body of the letter or report; the introduction and the conclusions ought not to bring any new information - they represent the "wrapping" of the text, converting it into a socially acceptable form. Thus, while the introduction puts forward the gist of the report, the conclusions summarize what has been said and possibly set the stage for a future business relationship. In-between, ideas must be adequately developed, using a variety of grammar and vocabulary structures and a moderate degree of complexity. It is sometimes a difficult challenge for the emitter to strike the right balance between conveying all the relevant information while at the same time avoiding information overload, and to write sentences that are complex without being heavy and convoluted. Similarly, in letters, although there is no clear structure like in reports, there is nonetheless an introductory paragraph putting forward the reason for writing, followed by the main body of the letter, which includes several paragraphs and lays out the main issues, and, usually, a concluding paragraph which is not supposed to convey any new content.

One further aspect that students sometimes overlook is related to the use of linkers. Loyal to their academic background, students tend to use a significant number thereof, in order to highlight the structure of the writing. However, since reports have a clear-cut structure (due to the existence of sub-headings, sections and subsections, possibly bullets and numbers), linkers are not as important in the overall economy of the text as they would be in a letter or in an essay. On the contrary, they may represent an infelicitous language choice, as they are essay-like in style, while their excessive use is clearly not in line with modern business writing standards. In business letters, linkers are more widely used and generally encouraged, since they participate to building a structure not rendered by any other means (such as sub-headings or separate sections).

Broadly speaking, when it comes to their ability to structure and convey content, students may also come across the challenge of identifying which facts are relevant for the purpose of writing. While "a well-structured document written in good business language is the core of effective communication" (Taylor, 2012: 51), a well-organised structure is sometimes difficult to accomplish. When writing a report or letter, the student should focus only on the facts that are relevant for the situation and flow logically from one another towards a natural conclusion. There is sometimes a fine line between too little information, just the right amount of information, and information overload; surprisingly, however, most students fall into the trap of providing too much rather than too little information. They sometimes refer to facts or situations that do not directly impact the issue at stake, 
thus turning the document into a longer, tiresome stretch of discourse. We believe that the root of this problem, too, can be traced back to their academic background where, under pressure to impress, to display their knowledge and mastery of a foreign language and to outperform their peers, they felt compelled to produce long-winded essays replete with complicated vocabulary and visibly complex grammar. However, in the business writing context, conciseness is of the essence: all the unnecessary stories, facts and information need to be dropped, while the student should focus on conveying the gist of the case in question. Equally, facts should be presented in the chronological order in which they occurred, thus rendering the reading and processing of the document an easy task and leading to the conclusions or recommendations section in a manner that is natural and easy to follow.

\section{Conclusions}

The business world of today is a highly competitive environment where every detail counts in initiating and maintaining a fruitful, successful, long-term partnership. In particular, the way business texts are written reflect on the image of both the employee, and of the company itself. The accurate and appropriate drafting of a text represents the business card of a company, the first impression it makes on potential business partners and on other collaborators. Likewise, an inadequately written text may negatively impact the company's image, conveying an impression of unprofessionalism, sloppiness and untrustworthiness. Possible outcomes may include short-term effects such as a decrease in sales and therefore profit, while the long-term consequences may affect future opportunities, leading to problems in networking or in the relations with the stakeholders (customers, employees, suppliers, partners etc.).

Hence, the ability to correctly, flexibly, adequately and efficiently write a text represents a fundamental business skill nowadays, a skill that gives an edge both to the employee and to the company in the local, national and international business environment. Among the most obvious advantages that stem from mastering this skill, we can think of an increased efficiency, fruitful relations with stakeholders, enhanced credibility and legitimacy in conducting business, and a good public image. All of the above bestow unmatched authority on a firm operating in the modern business world, characterized by fierce competitiveness and a constant race against the clock.

For all these reasons, we believe it is hugely important for students to be aware of the fact that using a language correctly is not enough, that there are other aspects to consider, such as flexibility and appropriateness, and to take steps towards understanding and using these fine nuances and thus improving their overall mastery of language. In our years of experience of teaching Business English, we have become aware of a number of ways in which students can be assisted in their attempt to refine their ability to write for professional purposes: besides classroom 
practice on the basis of templates and models, or analysis and discussion of samples of real-life documents and comparison with one's own and peer documents (see also David, 2013a.: 17-18), extensive reading in the target language also contributes to developing one's sense of what is appropriate in a given (business) context (we agree with Garner, 2012: xviii-xix, who also encourages those who want to become professional business writers to engage in reading well-written enjoyable material, to develop one's focus on "reader's needs" $[\ldots]$, a feel for natural idioms, $[\ldots]$ an appreciation for the right words in the right places, an ear for tone").

\section{References and bibliography}

Beaugrande, R. and Dressler, W. 1981. Introduction to Text Linguistics, London: Longman.

Boros, C. L. and Boros, L. L., 2012. The Fundamentals of Business Writing, Bloomington: Xlibris Corporation.

Canavor, Natalie. 2017. Business Writing for Dummies, New Jersey: John Wiley and Sons, Inc.

Crystal, David, Davy, Derek. 1975. Advanced Conversational English, London: Longman.

David, Irina. 2013a. "Developing Business English Writing Skills: Views of Students at the Bucharest University of Economic Studies". Synergy. 9 (1), 12-19, http://synergy.ase.ro/issues/2013-vol9-no-1/07-irina-david-developingbusiness-english-writing-skills-views-of-students-at-the-bucharestuniversity-of-economic-studies.pdf.

David, Irina. 2013b. Enhancing Communication Skills in English: A Prerequisite for Success, Bucureşti: Editura Universitară.

Dima, Viorela-Valentina. 2015. "The role of foreign language classes in the moulding of professional economists", in Nicolae, Mariana, Constantinescu-Ștefănel, Ruxandra (eds). 2015. The History of Modern Languages in the Bucharest University of Economic Studies. A centennial perspective, pp. 36-53. http://limbimoderne.ase.ro/docs/public/THEHISTORY-OF-MODERN-LANGUAGES.pdf.

Dima, Viorela-Valentina, Ștefan, Laura Raluca. 2021. "ESP Student Feedback A Tool to Develop both Students' and Teachers' Competences", Language Teaching Research Quarterly, 23, pp. 80-104, https://eurokd.com/ LTRQ/doi/10.32038/ltrq.2021.23.07.pdf.

Garner, B. A. 2012. HBR Guide to Better Business Writing. Boston: Harvard Business Review Press.

Ionel, Simona. 2010. „English in the Workplace”, în Mureșan, Laura Mihaela, Militaru, Marina. (eds.). 2010. Proceedings of the International Conference on Languages for Specific Purposes „Languages as a Lifeskill - New Perspectives on LSP Teaching and Learning” (CD), București: Editura 
ASE, 2010, pp. 273-286, https://www.sic.ase.ro/wp-content/uploads/sic2010/S2_6_Simona-Ionel_English-in-the-Workplace.pdf.

Lilleker, D.G. 2006. Key Concepts in Political Communication, London: Sage Publications.

Marinescu, R.E., Nicolae, M. and Şerban-Oprescu A.T. (eds), 2019. Comunicare 4.0. - Tratat de comunicare în afaceri internaționale, București: Editura A.S.E.

Merchan, L. 2018. “On Digital Strategy, Too Many Campaigns Still Don’t Get It", retrieved from https://www.campaignsandelections.com/campaigninsider/ on-digital-strategy-too-many-campaigns-still-don-t-get-it, accessed on April 3,2020 .

Mureșan, Laura-Mihaela. 2012. "Familiarising Students of Economics with a Genre-Based Approach to Academic Writing", in Lachout, Martin (ed.). 2012. Towards a More Specialised European Framework for (SelfAssessing Language Competencies, Prague: Metropolitan University Prague Press, 2012. 106-116.

Nordquist, R. 2019. What is register in linguistics? retrieved from https://www.thoughtco.com/register-language-style-1692038, accessed on July 2, 2020.

OECD. Quintini, G. (2014). Skills at Work: How Skills and their Use Matter in the Labour Market, OECD Social, Employment and Migration Working Papers, No. 158, OECD Publishing. Retrieved from http://dx.doi.org/ 10.1787/5jz44fdfjm7j-en.

Talbot, F. 2016. Outstanding Business English: Tips for email, social media and all your business communications, Madrid: Lid Editorial.

Taylor, S. 2012. Model Business Letters, Emails and Other Business Documents, London: Pearson.

Yule, G. 2020. The Study of Language, Cambridge: CUP.

\section{Internet resources}

Council of Europe, 2001. Common European Framework of Reference for Languages: learning, teaching, assessment, Cambridge: Cambridge University Press, https://rm.coe.int/1680459f97, accessed on July 6, 2020.

Council of the European Union. 2018. Council Recommendation of 22 May 2018 on key Competences for lifelong learning. Retrieved from https://eurlex.europa.eu/legalcontent/EN/TXT/PDF/?uri=CELEX:32018H0604(01)\&from=LT.

European Commission. 2012. "Special Eurobarometer 386. Europeans and Their Languages. Report", June 2012, https://nellip.pixel-online.org/files/ publications_PLL/19_Languages\%20for\%20Europe.pdf.

Lancaster University. not dated. Ling 131 Language \& Style course. Topic 2: Being creative with words and phrases, Department of Linguistics and 
English Language, Lancaster University, https://www.lancaster.ac.uk/fass/ projects/stylistics/topic2a/3conversion.htm, accessed on July 9, 2020.

Lund University. 2011. Academic Writing in English. Register types, https://awelu.srv.lu.se/grammar-and-words/register-and-style/registertypes/, accessed on July 6, 2020.

\section{The Authors}

Antonia Enache is an Associate Professor with the Department of Modern Languages and Business Communication at the Bucharest University of Economic Studies. She holds a $\mathrm{PhD}$ in Philology from the University of Bucharest (2006), an MA in European and International Relations and Management (University of Amsterdam, 2001) and an MA in Applied Linguistics (University of Bucharest, 1998). She is the author of several books in the field of political communication, such as Discursive Practices in Barack Obama's State of the Union Addresses (2017), Political Communication (co-author, 2013) and Promisiunea politică (2006) and has made numerous contributions to specialized scientific journals. Her main areas of interest include applied linguistics, political communication, economics, business communication and translation studies.

Associate Professor Marina Militaru, $\mathrm{PhD}$, is the author of many articles on political communication and English methodology. Among the books she has published as coauthor we mention Verbal versus nonverbal în comunicarea politică (2016) and Political Communication (2013). She currently teaches Business English at the Bucharest University of Economic Studies.

Viorela-Valentina Dima is an Associate professor with the Bucharest University of Economic Studies, Romania. She holds a BA degree in Romanian and English, an MA in Theoretical linguistics, and a $\mathrm{PhD}$ degree in Philology, all from the University of Bucharest. She is a professional translator and an ECQA Certified Terminology Manager. Her research areas include: theoretical and applied linguistics, foreign language teaching methodology, translation studies, higher education marketing. 